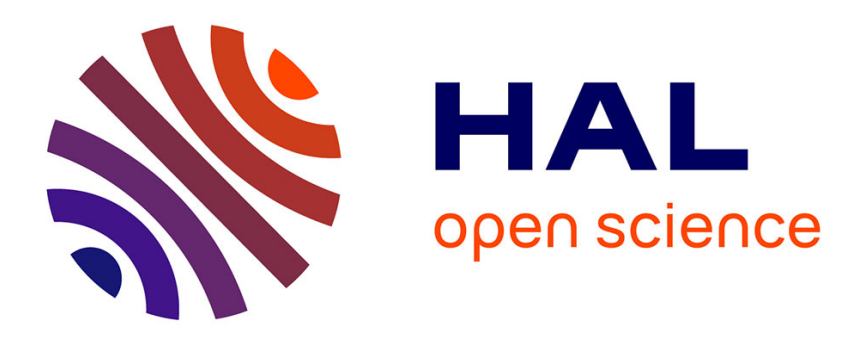

\title{
The Zinc-Ferro Ferrite System Revisited
}

\author{
V. Brabers
}

\section{To cite this version:}

V. Brabers. The Zinc-Ferro Ferrite System Revisited. Journal de Physique IV Proceedings, 1997, 07

(C1), pp.C1-233-C1-236. 10.1051/jp4:1997189 . jpa-00255136

\section{HAL Id: jpa-00255136 \\ https://hal.science/jpa-00255136}

Submitted on 1 Jan 1997

HAL is a multi-disciplinary open access archive for the deposit and dissemination of scientific research documents, whether they are published or not. The documents may come from teaching and research institutions in France or abroad, or from public or private research centers.
L'archive ouverte pluridisciplinaire HAL, est destinée au dépôt et à la diffusion de documents scientifiques de niveau recherche, publiés ou non, émanant des établissements d'enseignement et de recherche français ou étrangers, des laboratoires publics ou privés. 


\title{
The Zinc-Ferro Ferrite System Revisited
}

\author{
V.A.M. Brabers \\ Eindhoven University of Technology, Department of Physics, P.O. Box 513, 5600 Eindhoven, \\ The Netherlands
}

\begin{abstract}
Highly stoichiometric zinc ferrous ferrites $\mathrm{Zn}_{x} \mathrm{Fe}_{3 x} \mathrm{O}_{4}$ were prepared and characterized by magnetization, desaccommodation, electrical conductivity, thermal expansion and magnetostriction measurements. The results of the magnetization measurements indicate that up till $\mathrm{x}=0.5$ the magnetic structure is collinear, which led to the highest saturation magnetizations ever found in spinel ferrites. The thermal expansion experiments reveal that zinc is located on the tetrahedral sites and the cation distribution is not likely to be temperature dependent.The occurrence of the high saturation magnetization is discussed in relation to ionic and electronic ordering in the compounds $\mathrm{Zn}_{0.5} \mathrm{Fe}_{2.5} \mathrm{O}_{4}$ and $\mathrm{Zn}_{23} \mathrm{Fe}_{2} 1_{13} \mathrm{O}_{4}$.
\end{abstract}

\section{INTRODUCTION}

In the past, zinc substitution in spinel ferrites which caused an increase in saturation magnetization has led to a large number of ferrite materials for typical applications, in particular in the $\mathrm{MnZn}$ and $\mathrm{NiZn}$ ferrite systems. However, for certain purposes, one would like to have the disposal of materials with even higher saturation magnetization. The zinc-ferro ferrites $\left(\mathrm{Zn}_{\mathrm{x}} \mathrm{Fe}_{3-\mathrm{x}} \mathrm{O}_{4}\right)$ seemed now to be a prosperous system because of the relative large magnetization of pure $\mathrm{Fe}_{3} \mathrm{O}_{4}$ which can be enlarged substantially by Zn-substitution.

A first study by Stuyts et al. [1] showed indeed that high saturation magnetizations can be obtained for polycrystalline ceramic samples. Unfortunately, the magnetization data at $5 \mathrm{~K}$ deviate for zinc concentrations $\mathrm{x}>0.2$ from the values expected for an antiparallel spin configuration, which suggests the presence of canted spin structures. Dickoff et al. [2] studied the magnetic structure of the zinc-ferro ferrite system, using Mössbaver spectroscopy and magnetization measurements and found evidence of localized spin canting for $\mathrm{Zn}$-concentrations above $\mathrm{x}=0.4$. Stoppels et al. [3] reported on the possible application of monocrystalline zinc-ferrous ferrites for video recording heads. They observed a large room temperature magnetization for compositions between $0.2<\mathrm{x}<0.4$ but also a large magnetic disaccommodation around room temperature, which degrades the performance of these materials as recording heads. Nowadays, it is well known that also for zinc-ferrous ferrites, the strength of room temperature magnetic disaccommodation is proportional to the octahedral cation vacancy concentration [4] i.e. the oxygen non-stoichiometry, which means that the single crystalline materials used by Stoppels et al. are non-stoichiometric and this might affect the other properties as well. In fact, the major problem with the zinc ferrous system concerns the technological procedure for the preparation of stoichiometric compounds with a fixed $\mathrm{Zn}$-concentration, because of the simultaneously evaporation of metallic $\mathrm{Zn}$ and the oxydation-reduction of the iron ions. In this report it will be shown that if special care is taken to avoid $\mathrm{Zn}$ evaporation with the aim to obtain oxygen-stoichiometric materials, substantially different magnetization properties will be obtained.

A second topic of interest in the zinc ferrite system concerns the cation distribution. Although the end member $\mathrm{ZnFe}_{2} \mathrm{O}_{4}$ is not of practical use because this normal spinel is antiferromagnetic with a transition temperature around $10 \mathrm{~K}$ [5], it has been shown that " $\mathrm{ZnFe}_{2} \mathrm{O}_{4}$ " type materials can be ferrimagnetic at higher temperatures due to the cation inversion, i.e. the presence of $\mathrm{Fe}^{3+}$ in tetrahedral sites. These non-equilibrium distributions can be obtained by wet chemical preparation [6] and mechanical activation [7] and are also suggested to occur by a temperature dependent cation distribution [8]. If this last effect is real, a low $\mathrm{Zn}$ octahedral occupancy may influence the properties of the zinc-ferro ferrites. With thermal expansion measurements, it will be shown that this inversion is not an intrinsic property of stoichiometric $\mathrm{ZnFe}_{2} \mathrm{O}_{4}$ but is due to $\mathrm{Zn}$ deficiency and evaporation of zinc.

A third item concerns the $\mathrm{Fe}^{2+} / \mathrm{Fe}^{3+}$ ordering on octahedral sites, which is well known as the Verwey transition for the 1:1 ordering in $\mathrm{Fe}_{3} \mathrm{O}_{4}$. Since also $1: 3$ and $1: 5$ cationic ordering can occur on the octahedral sublattice in the spinel structure, it is worthwhile to investigate the possibility of such ordering for $\mathrm{Fe}^{2+} / \mathrm{Fe}^{3+}$ ions in $\mathrm{the}_{\mathrm{Zn}} \mathrm{Fe}_{3-\mathrm{x}} \mathrm{O}_{4}$ system with compositions $x=0.5$ and $x=2 / 3$. 


\section{EXPERIMENTAL}

Polycrystalline $\mathrm{Zn}_{2} \mathrm{Fe}_{3-\mathrm{x}} \mathrm{O}_{4}$ were prepared from mixtures of $\mathrm{Zn}$-oxalate and $\alpha-\mathrm{Fe}_{2} \mathrm{O}_{3}$. A first prefiring was carried out at $300^{\circ} \mathrm{C}$ in air to decompose the oxalate, after which a second prefiring was carried out at $700^{\circ} \mathrm{C}$ in air. The obtained products were ground and from the obtained powders pellets were isostatically pressed $\left(2500\right.$ bar) and sintered. $\mathrm{ZnFe}_{2} \mathrm{O}_{4}$ was sintered in air at $1000^{\circ} \mathrm{C}$ and the zinc-ferro ferrites were sintered at $1150^{\circ} \mathrm{C}$ in $\mathrm{CO}_{2}$ followed by an annealing procedure at $900^{\circ} \mathrm{C}$ in $\mathrm{CO}_{2} / \mathrm{CO}$ mixtures to establish the exact oxygen stoichiometry. Since there is no substantially zinc evaporation below $1200^{\circ} \mathrm{C}$ if zinc is already incorporated in the spinel structure, the pellets were slowly heated to the sintertemperature within 24 hours in order to realize the spinel formation reaction at a relatively low temperature and to avoid $\mathrm{Zn}$ evaporation. Also single crystals were prepared by a floating zone technique but in contrast to the ceramic materials, the actual $\mathrm{Zn}$-content of these samples was lower than the nominal value. For ceramic materials it was possible to achieve an exact $\mathrm{Zn}$-Fe ratio equal to the nominal one. X-ray diffraction techniques showed the samples to be free of impurity phases.

The magnetization measurements were performed using a SQUDD-magnetometer. The magnetic desaccommodation spectra were measured by Prof.dr. F. Walz, (MPI-Stuttgart), using an automated LC-oscillator technique [9]. The thermal expansion was measured with a home-build dilatometer based on a differential transformer as displacement recording system. The electrical conductivity was measured on rectangular samples with a four point configuration.

\section{RESULTS AND DISCUSSION}

The crystal structure and cation distribution in $\mathrm{ZnFe}_{2} \mathrm{O}_{4}$ was studied by O'Neill [8] with X-ray diffraction on quenched samples; smaller lattice parameters were found for specimens quenched from higher temperatures (maximum variation \pm $0.02 \%$ ). In fig. 1 thermal expansion traces are shown for "stoichiometric" $\mathrm{ZnFe}_{2} \mathrm{O}_{4}$ sintered at $1000^{\circ} \mathrm{C}(1)$, the same specimen but quenched from $1000^{\circ} \mathrm{C}$ and a specimen with a slight excess of Fe (3). From the temperature range above $500^{\circ} \mathrm{C}$, either a positive or a negative deviation in the linear expansion can be seen, depending on the exact composition. These results are indicative that the results obtained by O'Neill are not to be due to a temperature dependent cation distribution but may be more related to the formation of lattice defects i.e. cation vacancies. Moreover, no evidence for tetrahedral $\mathrm{Fe}^{3+}$ was found in the Mössbauer spectra, although an inversion degree of almost $20 \%$ was calculated from the $X$-ray-data [8]. The conclusion seems to be justified that the cation distribution is not so strongly temperature dependent in the zinc ferrite system as proposed by $O$ 'Neill and that in fact there is no or only very little octahedral zinc present, which makes the interpretation of the magnetic data more simple.

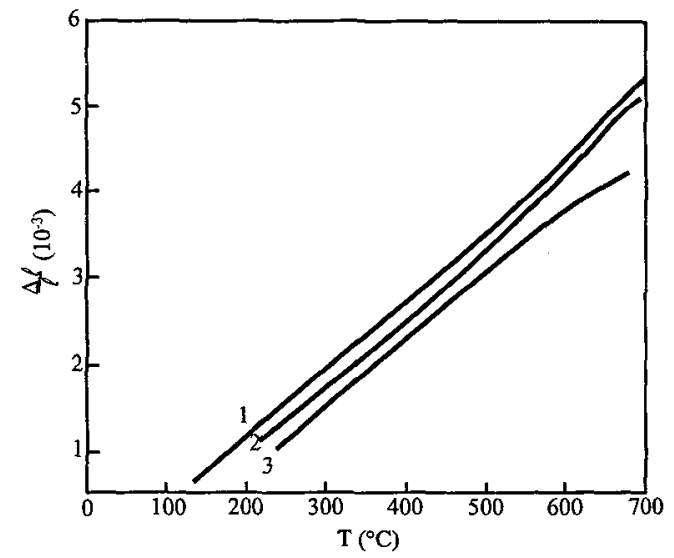

Fig. 1 Thermal expansion traces of $\mathrm{ZnFe}_{2} \mathrm{O}_{4}$

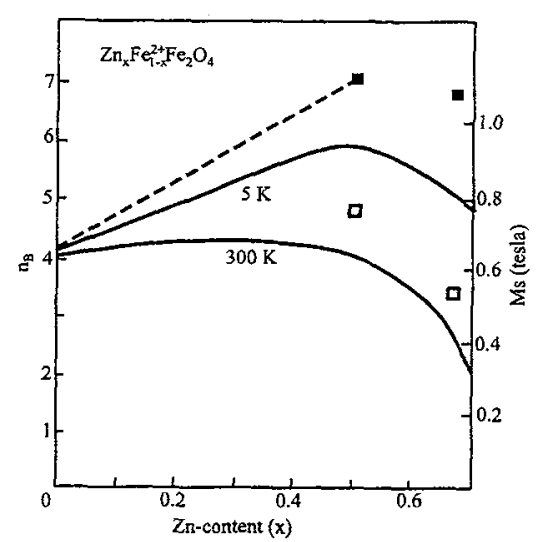

Fig. 2 Saturation magnetization of $\mathrm{Zn}_{x} \mathrm{Fe}_{3-\mathrm{x}} \mathrm{O}_{4}$ at 5 and $300 \mathrm{~K}$

In Fig. 2, the saturation magnetization data by Stuyts et al. [1] and our results for $x=0.5$ and $x=2 / 3$ are shown. We found at room temperature as well as at $5 \mathrm{~K}$ substantially higher values. For $\mathrm{x}=0.5$, the saturation magnetization at $5 \mathrm{~K}$ was even equal to the spin only value, supposing a collinear Néel configuration. In Fig. 3 and 4 the magnetization curves are shown for $x=0.5$ and $x=2 / 3$, respectively. Only the curves for $x=2 / 3$ and for $x=0.5$ at $300 \mathrm{~K}$ show a substantial high-field susceptibility, indicating non-saturation due to a possible spin canting, in contrast to the results of Dickof et al. [2], who found already at zine concentrations below $\mathrm{x}=0.5$ evidence for a substantial canting. The origin of these discrepancies must be found in the different quality and stoichiometry of the materials. 


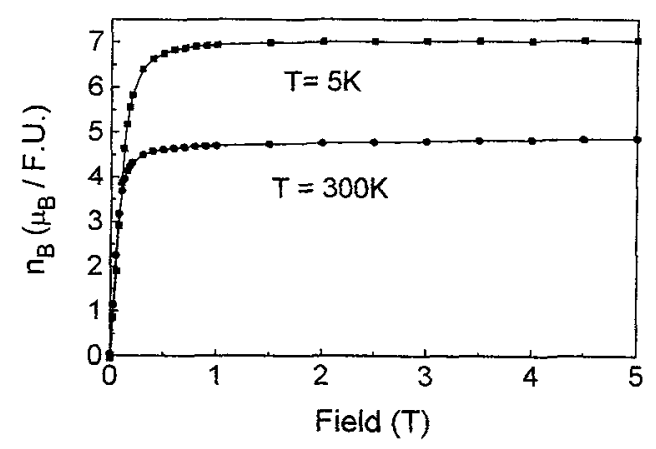

Fig. 3 Magnetization curves of stoichiometry $\mathrm{Zn}_{0.5} \mathrm{Fe}_{2.5} \mathrm{O}_{4}$

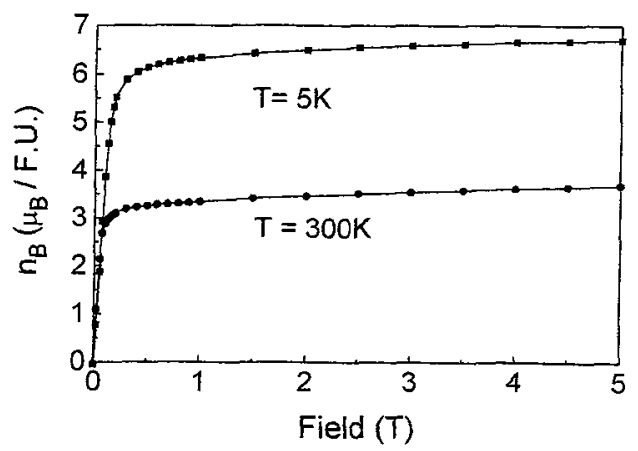

Fig. 4 Magnetization curves of stoichiometric $\mathrm{Zn}_{2 / 3} \mathrm{Fe}_{21 / 3} \mathrm{O}_{4}$

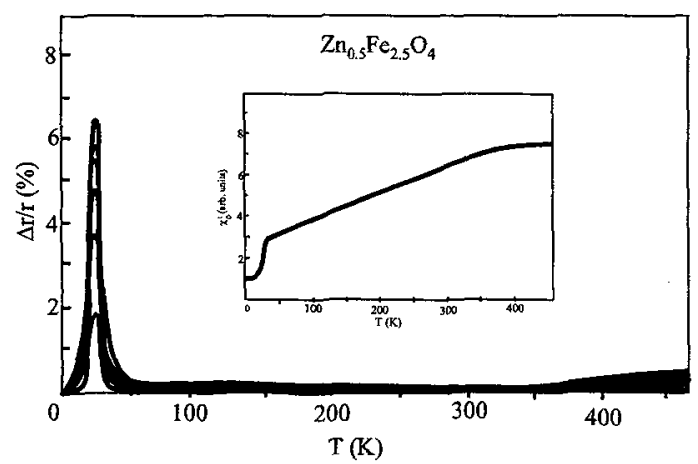

Fig. 5 Desaccommodation spectrum of stoichiometric $\mathrm{Zn}_{0.5} \mathrm{Fe}_{2.5} \mathrm{O}_{4}$

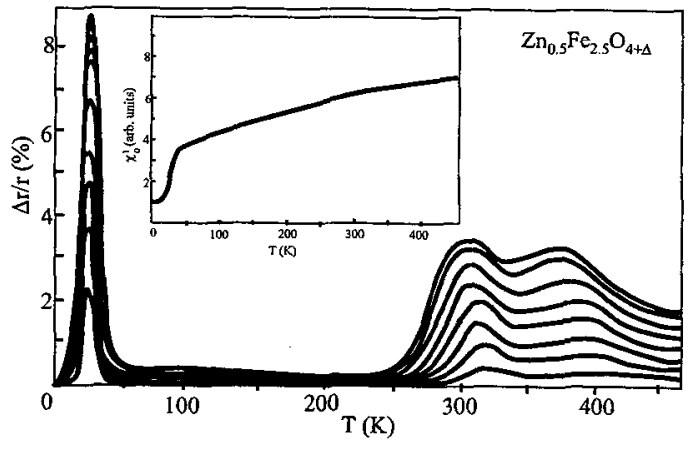

Fig. 6 Desaccommodation spectrum of non-stoichiometric $\mathrm{Zn}_{0.5} \mathrm{Fe}_{2.5} \mathrm{O}_{4+\Delta}$

In Fig. 5 and 6 the desaccommodation spectra of two zinc-ferro ferrites with $x=0.5$ are presented; the first with the exact oxygen stoichiometry prepared as described before and the second slightly oxidised. From the absence of the high temperature peaks in Fig. 5, which are in fact a probe for the non-stoichiometry of the ferrite, it is evident that our materials used for the magnetization experiments are highly stoichiometric. Similar results were also obtained for $\mathrm{x}=2 / 3$. A remarkable effect is that for the stoichiometric $x=0.5$ and $x=2 / 3$ only a low temperature MAE-peak is observed around $25 \mathrm{~K}$, which has to be of electronic origin. Whether this effect is related to some stress release around an octahedral defect $\left(\mathrm{Zn}^{2+}\right)[10]$ or is caused by $1: 3$ and $1: 5$ electron ordering transitions is at this moment not yet clear. There is a sudden increase in the magnetic permeability around $25 \mathrm{~K}$ as shown in the insets of Fig. 5 and 6 , indicating a drastic decrease of the magnetic anisotropy towards higher temperatures. Evidence for this decrease was also found in the magnetization versus temperature curves determined at several field strengths, not presented in this paper.

Long range electronic ordering should have a strong effect on the electrical resistivity (see f.i. the Verwey transition in $\mathrm{Fe}_{3} \mathrm{O}_{4}$ ). In Fig. 7 the preliminary results of the resistivity measurements on stoichiometric polycrystalline $\mathrm{Zn}_{0.5} \mathrm{Fe}_{2.5} \mathrm{O}_{4}$ are plotted; unfortunately, the experiments were up till now not yet extended below $30 \mathrm{~K}$, in order to see any effect around $25 \mathrm{~K}$. An additional problem with resistivity measurements on polycrystalline ferrites concerns the influence of grain bounderies which might have a different resistivity compared to the grains. However, measurements on a single crystal with approximately the composition $\mathrm{x}=0.5$ showed the same features as in Fig. 7 , which suggests that the results are not affected by the polycrystalline structure of our samples. The temperature range $100-50 \mathrm{~K}$ separates two regions which can be approximated with an exponential T-dependency with activation energies of 0.047 and $0.028 \mathrm{eV}$ for the high and low temperature regions, respectively. An explanation for the occurrence of these two regions might be a possible short-range order of the $\mathrm{Fe}^{2+}-\mathrm{Fe}^{3+}$ ions, due to Coulomb interactions, which influenced the electron transport at lower temperatures. Long range ordering in the spinel structure, however, is predominantly caused by second-neighbour 
interactions [11], which implies that also the occupation of the tetrahedral sublattice plays an important role. Although 1:1 and 1:2 cationic ordering on A-sites in the spinel structure is possible, it is unlikely that this occurs in the zinc-ferrites with $x=0.5$ and $2 / 3$ because of the low ionic diffusion at lower temperatures. However, short range A-site order may persist, which could be one of the reasons for the differences in magnetic properties we have found. For the electrical properties this denotes also that a complete electron ordering on the octahecral sites is hampered by tetrahedral disorder, which obscures any first order transition. The transition range between $100-50 \mathrm{~K} \mathrm{might} \mathrm{be} \mathrm{a} \mathrm{result} \mathrm{of} \mathrm{this.} \mathrm{To} \mathrm{study} \mathrm{this} \mathrm{in} \mathrm{more}$ detail, annealing experiments to allow A-site ordering to take place are still in progress.

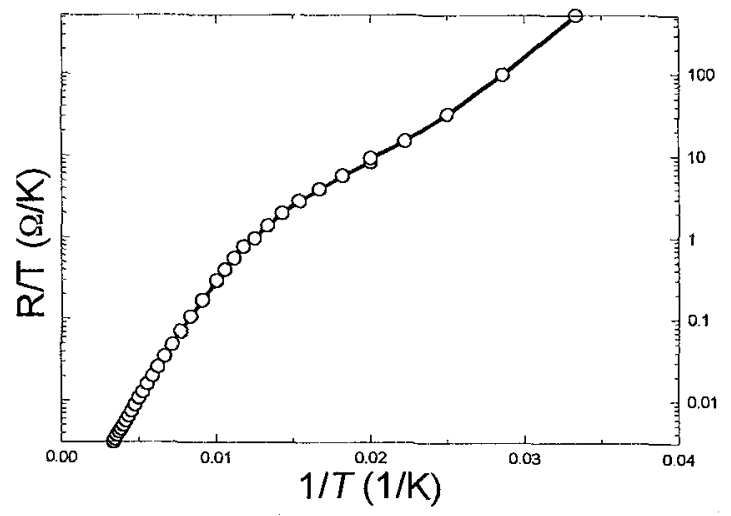

Fig. 7 Electrical resístance versus reciprocal tenperature of stoichiometric polycrystalline $\mathrm{Zn}_{0.5} \mathrm{Fe}_{2.5} \mathrm{O}_{4}$

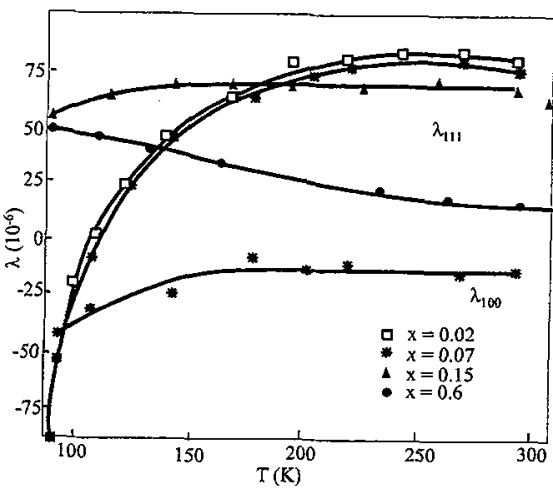

Fig. 8 Magnetostriction constants $\lambda_{11}$ and $\lambda_{100}$ of $\mathrm{Zn}_{\mathrm{x}} \mathrm{Fe}_{3 \cdot \mathrm{x}} \mathrm{O}_{4}$

For applications, besides a high magnetization, it is also desirable to realize a high permeability which means a low anisotropy, low magnetostriction and a suitable microstructure. In Fig. 8 magnctostriction data for some zinc ferro ferrites are presented, which were determined by the strain gauge technique on single crystals. The magnetostriction in the composition range of interest is still substantial at room temperature i.e. $\lambda_{111} \sim+15.10^{-6}$ and $\lambda_{100} \sim-15.10^{-6}$. How the magnetostriction and anisotropy can be further affected by annealing or by small cationic substitutions, meanwhile preserving the high saturation magnetization, has to be still investigated further.

\section{References}

[1] Stuyts A.L., Veeneman D. and Broese van Groenou A.B., Proc. Int. Conf. Ferrites, Kyoto, July 1970, Japan, p. 236.

[2] Dickof P.A., Schurer P.J. and Morrish A.H., Phys. Rev. B 22 (1980) 115.

[3] Stoppels D., Boonen P.G.T., Enz U. and van Hoof L.A.H., J. Magn. Magn. Mat. 37 (1983) 116.

[4] de Francisco C., Muñoz J.M., Ayala J. and Iñiguez J.I., Phys. Stat. Solidi (a) 108 (1988) 721.

[5] König U., Bertaut E.F., Gros Y. and Chol G., J. de Physique 32 (1971) C1-320.

[6] Kamiyama T., Haneda K., Sato T., Ikeda S. and Asano H., Solid State Communications 81 (1992) 563.

[7] Ermakov A.E., Yurchikov E.E., Elsukov E.P. Barinov V.A. and Chukalgin Yu.G., Sov. Phys. Solid State 24 (1982) 1112.

[8] O'Neill H.St.C., Eur. J. Mineral. 4 (1992) 571.

[9] Walz F., Phys. Status Solidi A147 (1995) 237.

[10] Walz F., Brabers V.A.M. and Kronmüller, ICF-7, Bordeaux (1996).

[11] de Bergevin F. and Brunel M., Compt. Rend. Acad. Sc. Paris 262 (1966) 1294. 